\title{
EFFECT SIZE MODEL PEMBELAJARAN KOOPERATIF TIPE NUMBERED HEADS TOGETHER (NHT) TERHADAP KEMAMPUAN BERPIKIR KRITIS SISWA PADA PEMBELAJARAN FISIKA
}

\author{
Widya Wati ${ }^{1}$, Rini Fatimah ${ }^{2}$ \\ 1,2Prodi Pendidikan Fisika FTK IAIN Raden Intan Lampung; widyawati@radenintan.ac.id \\ Diterima: 21 Agustus 2016. Disetujui: 12 Oktober 2016. Dipublikasikan: Oktober 2016
}

\begin{abstract}
The purpose of this research is to know the effect size of cooperatif learning model to critical thinking skills students at physics learning Class 8th grade Junior High School 24 Bandar Lampung. The type of this research was a quasi experimental with pretest - posttest control group design. The research involved two groups of students who accounted for 34 students for experiment class and 36 students for control class. The collection of data obtained using a test instrument shaped essay at critical thinking skills level. The results show that cooperative learning model type NHT have effect to critical thinking skills on effect size index 0,7. The effect size index 0,7 show that NHT to outcome critical thinking skills of students i.e $62 \%$ better than control class. Experiment class is better than control class at random sampling are 0,58 it means each one of 100 random sampling give effect for 58 sampling to improve critical thinking skills of students at learning physics.
\end{abstract}

\begin{abstract}
Abstrak: Penelitian ini bertujuan untuk mengetahui effect size dari model pembelajaran kooperatif tipe numbered heads together (NHT) terhadap kemampuan berpikir kritis siswa pada pembelajaran fisika kelas VIII SMP Negeri 24 Bandar Lampung. Jenis penelitian ini adalah quasi eksperimen dengan pretest - posttest control group design. Penelitian ini melibatkan 2 kelompok belajar siswa yang berjumlah 34 siswa untuk kelas Eksperimen dan 36 siswa untuk kelas kontrol. Pengumpulan data diperoleh dengan menggunakan instrumen tes berbentuk essay pada level kognitif kemampuan berpikir kritis. Diperoleh hasil penelitian bahwa model pembelajaran kooperatif tipe NHT mempunyai pengaruh terhadap kemampuan berpikir kritis pada pembelajaran fisika dengan indeks effect size sebesar 0,3. Effect size 0,3 ini menunjukkan bahwa NHT dapat menghasilkan outcome kemampuan berpikir kritis siswa sebesar $58 \%$ lebih baik dari kelas kontrol. Kelebihan kelas eksperimen dari kelas kontrol dalam pengambilan sampel acak sebanyak 0,58 artinya pada setiap 100 sampel acak NHT dapat mempengaruhi 69 sampel untuk meningkatkan kemampuan berpikir kritis siswa pada pembelajaran fisika.
\end{abstract}

(C) 2016 Pendidikan Fisika, FTK IAIN Raden Intan Lampung

Kata kunci: effect size, NHT, berpikir kritis, pembelajaran fisika

\section{PENDAHULUAN}

Berpikir kritis merupakan indikator kesuksesan dalam pembelajaran (York, Gibson, \& Rankin, 2015). Proses berpikir kritis dalam pembelajaran merupakan suatu kebutuhan yang perlu dijaga dan dikembangkan (Miller, Chahine, \& Childs, 2010; Beaumont, 2010). Proses berpikir kritis juga merupakan proses kognitif, dalam pembelajaran dimulai dengan mengidentifikasikan permasalahan, menganalisa dan kemudian mengevaluasi pembelajaran (Lau \& Chan, 2016; Paul \& Elder, 2008; Abrami, et al., 2015; Greene \& Yu, 2016). Proses mengidentifikasi, menganalisa, dan mengevaluasi dalam taksonomi bloom berada pada level kognitif tiga sampai level lima (Krathwohl, 2002).

Kemampuan tingkat berpikir dikembangkan dalam pembelajaran (Wati, 2012). Pembelajaran fisika mampu mengembangkan tingkat berpikir dengan baik melalui kegiatan ilmiah yang 
dilakukan (Wati, Asyhari, \& Diani, 2016). Kegiatan ilmiah dalam pembelajaran fisika membantu siswa membangun konsep, prinsip, teori sebagai dasar untuk berpikir kritis dan kreatif (Wati \& Novianti, 2016; Henderson, Mestre, \& Slakey, 2015 Peter Haussler, 2000; Sin, 2014).

Badan Standar Nasional Pendidikan (BSNP, 2006) menyatakan salah satu tujuan pembelajaran fisika di sekolah adalah mengembang kemampuan bernalar dalam berpikir analisis induktif dan deduktif dengan menggunakan konsep dan prinsip fisika untuk menjelaskan berbagai peristiwa alam dan menyelesaikan masalah baik secara kualitatif maupun kuantitatif. Untuk itu, berpikir kritis dalam pembelajaran fisika sangat diperlukan, agar konsep fisika dibangun dengan benar dan tercapainya tujuan pembelajaran fisika di sekolah.

Penerapan berpikir kritis dalam pembelajaran perlu didukung dengan active learning. Active learning membuat setiap siswa aktif dalam pembelajaran. Tileston (2007) memaparkan beberapa model pembelajaran yang dapat digunakan untuk active learning, seperti numbered heads together (NHT). Langkah pembelajaran NHT dimana setiap siswa dalam grup diberi nomer, kemudian guru memberi pertanyaan dan batas waktu untuk menjawab. Selanjutnya, siswa menyampaikan pendapat masing-masing dalam kelompok dan memulai diskusi. Terakhir, guru menyebutkan nomer siswa, untuk menjawab pertanyaan mewakili pendapat kelompoknya. NHT memungkinkan siswa untuk aktif dalam pembelajaran dan meningkatkan proses berpikir.

Pembelajaran kelas menuntut partisipasi aktif untuk semua siswa, baik siswa yang kemampuannya kurang maupun siswa yang kemampuannya baik. Partisipasi aktif siswa dalam pembelajaran dapat membangun proses berpikir yang lebih baik. Untuk itu, model pembelajaran kooperatif dengan tipe NHT yang merupakan salah satu active learning yang dapat digunakan untuk meningkatkan proses berpikir kritis siswa (Baker, 2013).

Penelitian ini, dimaksudkan untuk mengetahui effect size model pembelajaran kooperatif tipe NHT terhadap kemampuan berpikir kritis siswa pada pembalajaran fisika. Effect Size merupakan metode meta analisis (Coe, 2002) yang digunakan untuk menentukan efektivitas dari sebuah penelitian baik praktik atau teori, kontribusi relatif dari faktor yang berbeda atau faktor yang sama pada persoalan yang berbeda dan menunjukkan kekuatan sebuah analisis pada penelitian (Lakens, 2013; Fritz \& Morris, 2012; Cohen, 1992). Effect Size pada penelitian ini digunakan untuk melihat seberapa besar NHT memperngaruhi kemampuan berpikir kritis, bagaimana kualitas hubungan antara NHT dan kemampuan berpikir kritis serta outcome yang dihasilkan dari NHT terhadap kemampuan berpikir kritis.

\section{LANDASAN TEORI}

\section{Model Pembelajaran Kooperatif tipe Numered Heads together (NHT)}

Model pembelajaran merupakan kerangka konseptual berupa pola prosedur sistematik yang dikembangkan berdasarkan teori dan digunakan dalam mengorganisasikan proses pembelajaran (Sani, 2014). Model pembelajaran mempunyai ciri khas yakni adanya sintaks atau tahapan pembelajaran.

Salah satu model pembelajaran adalah model pembelajaran kooperatif. Melalui model pembelajaran kooperatif, siswa bukan hanya belajar dan menerima apa yang disajikan oleh guru dalam proses belajar mengajar, melainkan bisa juga belajar dari siswa lainnya, dan sekaligus mempunyai kesempatan untuk membelajarkan siswa yang lain (Slavin, 2009). Proses pembelajaran dengan model pembelajaran kooperatif ini mampu merangsang dan menggugah potensi siswa secara optimal dalam suasana belajar 
dalam kelompok-kelompok kecil yang terdiri dari 2 sampai 6 orang siswa (Wati, 2009).

Model pembelajaran kooperatif mempunyai banyak tipe pembelajaran. Salah satu tipe model pembelajaran kooperatif yang baik adalah numbered heads together (NHT) karena menjadikan setiap siswa akif dalam pembelajaran (Tileston, 2007). Langkah pembelajaran tpe NHT sebagai berikut:

a. Bentuk kelompok diskusi yang beranggotaan 4 orang

b. Beri nomer untuk setiap siswa 1-4

c. Guru memberikan pertanyaan kedapa siswa dan batas waktu pengerjaan

d. Masing-masing siswa menyampaikan pendapatnya dalam kelompok dan mendiskusikan jawaban dari pertanyaan guru

e. Setelah selesai diskusi, guru menyebutkan nomer siswa, dan siswa menyampaikan hasil diskusi mewakili grup

\section{Berpikir Kritis}

Berpikir kritis merupakan hasil pembelajaran. Proses berpikir kritis merupakan proses kognitif, dalam pembelajaran dimulai dengan mengidentifikasikan permasalahan, menganalisa dan kemudian mengevaluasi pembelajaran (Lau \& Chan, 2016; Paul \& Elder, 2008; Abrami, et al., 2015; Greene \& Yu, 2016). Proses mengidentifikasi, menganalisa, dan mengevaluasi dalam taksonomi bloom berada pada level kognitif tiga sampai level lima (Krathwohl, 2002).

Cara yang dapat digunakan untuk menjadikan siswa dapat berpikir kritis adalah dengan memberikan petunjuk strategis dalam pembelajaran yang memungkinkan siswa dapat aktif, memberikan kesempatan siswa untuk mendiskusikan pendapatnya sesuai konten, dan menggunakan asesmen yaang sesuai dengan kemampuan berpikir kritis (Peter, 2012).

\section{METODE PENELITIAN}

Penelitian ini digunakan metode Quasi Eksperiment Design. Penelitian ini dilakukan di SMP Negeri 24 Bandar Lampung Tahun Ajaran 2015/2016. Desain penelitian yang digunakan dalam penelitian ini adalah desain Pretest Posttest kontrol grup (Pretest - Posttest Control-Group Design), dengan desain nya dapat dilihat pada tabel 1 berikut.

Tabel 1. Desain Penelitian

\begin{tabular}{cccc}
\hline Kelas & Prates & Perlakuan & Pascates \\
\hline VIII E & $\mathrm{O}$ & $\mathrm{X}_{\mathrm{T}}$ & $\mathrm{O}$ \\
VIII C & $\mathrm{O}$ & $\mathrm{X}_{\mathrm{C}}$ & $\mathrm{O}$ \\
\hline (Johnson, 2016) & &
\end{tabular}

Desain Pretest - Posttest kontrol grup, satu kelompok merupakan kelompok eksperimen yang diberi perlakuan, satu kelompok lagi merupakan kelompok kontrol.

Variabel dalam penelitian ini terdiri dari dua variabel yaitu hubungan antara variabel bebas $(\mathrm{X})$ dan variabel terikat $(\mathrm{Y})$ yang dapat dilihat pada gambar 1 (Sugiyono, 2008) berikut.

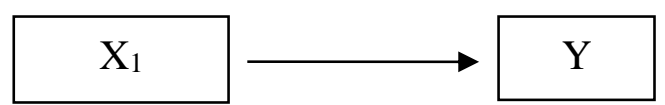

Gambar 1. Bentuk variabel penelitian

Keterangan:

1. Variabel Bebas (x) merupakan variabel yang mempengaruhi atau yang menjadi sebab perubahan atau timbulnya variabel terikat. Pada penelitian ini variabel bebas adalah Model Pembelajaran Kooperatif Tipe NHT (Numbered Head Together)

2. Variabel Terikat (y) adalah variabel yang dipengaruhi atau yang menjadi akibat, karena adanya variabel bebas. Variabel 
terikat pada penelitian ini adalah kemampuan berpikir kritis siswa

\section{Populasi, Sampel dan Teknik Pengambilan Sampel}

1. Populasi

Populasi pada penelitian ini adalah seluruh siswa kelas VIII semester genap SMP Negeri 24 Bandar Lampung Tahun Ajaran 2015/2016.

2. Sampel

Sampel yang akan diambil dalam penelitian ini adalah dua kelas, yaitu Kelas VIII C dan Kelas VIII E SMP Negeri 24 Bandar Lampung tahun ajaran 2015/2016.

3. Teknik Pengambilan Sampel

Teknik Pengambilan Sampel yang digunakan pada penelitian ini adalah Teknik Pengambilan Random Sampling atau sampel acak.

\section{Teknik Pengumpulan Data}

Untuk memperoleh data dalam penelitian, peneliti menggunakan beberapa metode pengumpulan data, di antaranya adalah sebagai berikut:

1. Dokumentasi

2. Wawancara

3. Tes Kemampuan Berpikir Kritis

4. Metode Studi Kepustakaan

\section{Uji coba instrumen}

1. Uji Validitas

Untuk mengetahui validitas butir soal digunakan rumus pada persamaan 1 (Sugiono, 2013) berikut.

$\boldsymbol{r}_{\boldsymbol{x} \boldsymbol{y}}=\frac{N \sum \boldsymbol{X} \boldsymbol{Y}-\left(\sum \boldsymbol{X}\right)\left(\sum \boldsymbol{Y}\right)}{\sqrt{\left.\left.\left[N \sum \boldsymbol{X}^{2}-\left(\sum \boldsymbol{X}\right)^{2}\right)\right]\left[N \sum \boldsymbol{Y}^{2}-\left(\sum \boldsymbol{Y}\right)^{2}\right)\right]}}$

Jika $r_{x y}$ di bawah 0,30 , maka dapat disimpulkan bahwa butir instrumen tersebut tidak valid, sehingga harus diperbaiki atau dibuang.

2. Uji Tingkat Kesukaran

Menghitung tingkat kesukaran butir tes digunakan rumus pada persamaan 2 (Abidin, 2016) berikut.

$T K=\frac{B_{A}}{\eta_{A}}+\frac{B_{B}}{\eta_{B}}$

Tabel 2. Kriteria indeks kesukaran

\begin{tabular}{ll}
\hline Nilai (TK) & Kriteria \\
\hline $0,00 \geq \mathrm{p} \geq 0,25$ & Sukar \\
$0,25<\mathrm{p} \leq 0,75$ & Sedang \\
$0,75<\mathrm{p} \leq 1,00$ & Mudah \\
\hline
\end{tabular}

3. Uji Daya Beda

Indeks daya pembeda dapat dicari dengan menggunakan rumus pada persamaan 3 (Abidin, 2016) berikut.

$D P=\frac{B_{A}}{\eta_{A}}-\frac{B_{B}}{\eta_{B}}$

Tabel 3. Klasifikasi daya pembeda

\begin{tabular}{ll}
\hline \multicolumn{1}{c}{ DP } & \multicolumn{1}{c}{ Kriteria } \\
\hline DP $\geq 0,40$ & Baik \\
$0,20 \leq$ DP $<0,40$ & Cukup \\
DP $<0.20$ & Kurang \\
\hline
\end{tabular}

4. Uji Reliabilitas

Perhitungan uji reliabilitas dengan menggunakan rumus Alpha pada persamaan 4 (Arikunto, 2013)berikut.

$$
r_{11}=\left(\frac{n}{n-1}\right)\left(1-\frac{\sum \sigma_{i}^{2}}{\sigma_{t}{ }^{2}}\right)
$$

Koefisien reliabilitas yang diperoleh diinterpretasikan terhadap koefisien reliabilitas tes yang pada umumnya digunakan patokan sebagai berikut:

a) Apabila $r_{\text {hitung }} \geq 0,70$ berarti tes kemampuan komunikasi matematis yang sedang diuji reliabilitasnya dinyatakan telah memiliki reliabilitas yang tinggi.

b) Apabila $r_{\text {hitung }}<0,70$ berarti tes kemampuan komunikasi matematis yang sedang diuji reliabilitasnya dinyatakan belum memiliki reliabilitas yang tinggi

\section{Pengambilan Kesimpulan Butir Soal}

Berdasarkan hasil perhitungan dan analisis uji validitas, tingkat kesukaran, daya beda dan uji reliabilitas butir soal kemampuan berpikir kritis. Soal yang digunakan dalam penelitian ini sebagai tes kemampuan berpikir kritis fisika di Kelas Eksperimen dan Kelas Kontrol adalah soal-soal yang memenuhi kriteria. Berdasarkan hasil perhitungan, diketahui 
bahwa dari 12 soal uraian terdapat 7 soal yang dinyatakan diterima dan 5 soal yang dinyatakan ditolak. Selanjutnya, soal yang dinyatakan diterima digunakan sebagai instrumen tes berjumlah 7 soal pretest dan postes yang digunakan dalam penelitian ini.

\section{Teknik Analisis Data}

Setelah data terkumpul, data di analisis dengan menggunakan langkah-langkah sebagai berikut:

\section{Uji Normalitas}

Uji normalitas data dilakukan untuk mengetahui apakah data yang diperoleh dari populasi yang berdistribusi normal atau tidak dengan menggunakan rumus lilliefors. Dengan langkah- langkah sebagai berikut:

a) Hipotesis

$H_{o}$ : Sampel berasal dari populasi yang berdistribusi normal

$H_{1}$ : Sampel tidak berasal dari populasi yang berdistribusi normal

b) Taraf Signifikan $(\alpha)=0,05$

c) Statistik uji

d) Keputusan uji $H_{o}$ ditolak jika $L_{\text {hitung }}$ terletak didaerah kritis.

e) Kesimpulan

1. Sampel berasal dari populasi yang berdistribusi normal jika $H_{o}$ diterima

2. Sampel berasal dari populasi yang tidak berdistribusi normal jika $H_{o}$ ditolak.

Selanjutnya nilai $\mathrm{L}$ tersebut dibandingkan dengan $\mathrm{L}$ pada tabel dengan mengambil nilai $\alpha=0,05$. Jika L hitung lebih kecil dari $\mathrm{L}$ tabel maka sampel berasal dari populasi yang normal.

2. Uji Homogenitas

Uji ini untuk mengetahui kesamaan antar dua keadaan atau proporsi. Uji homogenitas yang digunakan adalah uji homogenitas dua varians atau uji fisher.
Dengan langkah-langkah sebagai berikut:

a. Rumuskan Hipotesis

$$
\begin{gathered}
\mathrm{H}_{0}: \sigma_{1}^{2}=\sigma_{2}^{2} \text { (varians } 1 \text { sama } \\
\text { dengan varians } 2 \text { atau }
\end{gathered}
$$
homogen)

$H_{\mathrm{a}}: \sigma_{1}^{2} \neq \sigma_{2}^{2}$ (varians 1 tidak sama dengan varians 2 atau tidak homogen).

b. Bagi data menjadi dua kelompok

c. Cari varians masing-masing kelompok

d. Tentukan $\mathrm{F}$ hitung dengan rumus:

$$
\begin{aligned}
& \mathrm{F}=\frac{\mathrm{S}_{1}^{2}}{\mathrm{~S}_{2}^{2}} \text { dimana, } \\
& \mathrm{S}^{2}=\frac{n \sum x^{2}-\left(\sum x\right)^{2}}{n(n-1)}
\end{aligned}
$$

e. Menentukan taraf signifikan $(\alpha)$

f. Hitung $F_{\text {tabel }}$ dengan rumus:

$\mathbf{F}_{\text {tabel }}=\mathbf{F} \frac{\mathbf{1}}{\mathbf{2}} \boldsymbol{\alpha}(\mathrm{dk}$ varians terbesar -1 , $\mathrm{dk}$ varians terkecil - 1)

g. Menentukan kriteria pengujian:

Dengan Hipotesis:

$\mathrm{H}_{0}$ : Data Homogen

$\mathrm{H}_{\mathrm{a}}$ : Data tidak Homogen

Kriteria Pengujian:

Jika $F_{\text {hitung }} \leq \mathrm{F}_{\text {tabel }}$ maka $\mathrm{H}_{0}$ diterima (homogen)

Jika $F_{\text {hitung }}>F_{\text {tabel }}$ maka $\mathrm{H}_{\mathrm{a}}$ diterima (tidak homogen)

3. Uji t

Uji $\mathrm{t}$ ini dilakukan dengan menggunakan rumus uji $t$ pada persamaan 7 (Anas, 2013) berikut.

$$
\mathrm{t}=\frac{M_{X}-M_{Y}}{\sqrt{\left(\frac{\left(\sum x^{2}+\sum y^{2}\right.}{\mathrm{n}_{1}+\mathrm{n}_{2}-2}\right)\left(\frac{\mathrm{N} 1+N 2}{\mathrm{~N} 1 \times \mathrm{N} 2}\right)}}
$$

Ho : Tidak terdapat pengaruh model pembelajaran Kooperatif Tipe NHT (Numbered Head Together) terhadap kemampuan berpikir kritis peserta didik. 
$\mathrm{H}_{1}$ : Terdapat pengaruh model pembelajaran Kooperatif Tipe NHT (Numbered Head Together) terhadap kemampuan berpikir kritis peserta didik

Adapun kriteria pengujiannya adalah:

- $\quad \mathrm{H}_{0}$ ditolak, jika $\mathrm{t}_{\text {hitung }}>\mathrm{t}_{\text {tabel }}$, dalam hal ini $\mathrm{H}_{1}$ diterima
- $\mathrm{H}_{0}$ diterima, jika $t_{\text {hitung }}<\mathrm{t}_{\text {tabel }}$, dengan $\alpha=0,05(5 \%)$.

\section{Uji Effect Size}

Cara menghitung effect Size dapat dilihat pada persamaan 8 (Hake, 2002; Cohen, 1988) berikut.

$$
E S=\frac{M_{A}-M_{B}}{\sqrt{\frac{\sigma_{A}^{2}+\sigma_{B}^{2}}{2}}}
$$

Tabel 4. Interpretasi nilai ES (Coe, 2002)

\begin{tabular}{|c|c|c|c|c|c|}
\hline $\begin{array}{l}\text { Effect } \\
\text { Size }\end{array}$ & $\begin{array}{l}\text { Percentage of } \\
\text { control group } \\
\text { who would be } \\
\text { below average } \\
\text { person in } \\
\text { experimental } \\
\text { group }\end{array}$ & $\begin{array}{l}\text { Rank of person } \\
\text { in a control } \\
\text { group of } 25 \text { who } \\
\text { would be } \\
\text { equivalent to } \\
\text { the average } \\
\text { person in } \\
\text { experimental } \\
\text { group }\end{array}$ & $\begin{array}{l}\text { Probability that } \\
\text { you could guess } \\
\text { which group a } \\
\text { person was in } \\
\text { from knowledge } \\
\text { of their 'score'. }\end{array}$ & $\begin{array}{l}\text { Equivalent } \\
\text { correlation, } r \\
\text { (=Difference in } \\
\text { percentage } \\
\text { 'successful' in } \\
\text { each of the two } \\
\text { groups, BESD) }\end{array}$ & $\begin{array}{l}\text { Probability that } \\
\text { person from } \\
\text { experimental } \\
\text { group will be } \\
\text { higher than } \\
\text { person from } \\
\text { control, if both } \\
\text { chosen at } \\
\text { random } \\
\text { (=CLES) }\end{array}$ \\
\hline 0.0 & $50 \%$ & $13^{\text {th }}$ & 0.50 & 0.00 & 0.50 \\
\hline 0.1 & $54 \%$ & $12^{\text {th }}$ & 0.52 & 0.05 & 0.53 \\
\hline 0.2 & $58 \%$ & $11^{\text {th }}$ & 0.54 & 0.10 & 0.56 \\
\hline 0.3 & $62 \%$ & $10^{\text {th }}$ & 0.56 & 0.15 & 0.58 \\
\hline 0.4 & $66 \%$ & $9^{\text {th }}$ & 0.58 & 0.20 & 0.61 \\
\hline 0.5 & $69 \%$ & $8^{\text {th }}$ & 0.60 & 0.24 & 0.64 \\
\hline 0.6 & $73 \%$ & $7^{\text {th }}$ & 0.62 & 0.29 & 0.66 \\
\hline 0.7 & $76 \%$ & $6^{\text {th }}$ & 0.64 & 0.33 & 0.69 \\
\hline 0.8 & $79 \%$ & $6^{\text {th }}$ & 0.66 & 0.37 & 0.71 \\
\hline 0.9 & $82 \%$ & $5^{\text {th }}$ & 0.67 & 0.41 & 0.74 \\
\hline 1.0 & $84 \%$ & $4^{\text {th }}$ & 0.69 & 0.45 & 0.76 \\
\hline 1.2 & $88 \%$ & $3^{\text {rd }}$ & 0.73 & 0.51 & 0.80 \\
\hline 1.4 & $92 \%$ & $2^{\text {nd }}$ & 0.76 & 0.57 & 0.84 \\
\hline 1.6 & $95 \%$ & $1^{\text {st }}$ & 0.79 & 0.62 & 0.87 \\
\hline 1.8 & $96 \%$ & $1^{\mathrm{st}}$ & 0.82 & 0.67 & 0.90 \\
\hline 2.0 & $98 \%$ & $\begin{array}{c}1^{\text {st }}\left(\text { or } 1^{\text {st }} \text { out of }\right. \\
44)\end{array}$ & 0.84 & 0.71 & 0.92 \\
\hline 2.5 & $99 \%$ & $\begin{array}{c}1^{\text {st }}\left(\text { or } 1^{\text {st }} \text { out of }\right. \\
160)\end{array}$ & 0.89 & 0.78 & 0.96 \\
\hline 3.0 & $99.9 \%$ & $\begin{array}{c}1^{\text {st }}\left(\text { or } 1^{\text {st }} \text { out of }\right. \\
740) \\
\end{array}$ & 0.93 & 0.83 & 0.98 \\
\hline
\end{tabular}




\section{HASIL DAN PEMBAHASAN}

Penelitian dilakukan di dua kelas sebagai sampel yaitu Kelas VIII E sebagai kelas eksperimen dan Kelas VIII C sebagai kelas kontrol. Kelas eksperimen 1 menggunakan model pembelajaran kooperatif tipe NHT (Numbered Head Together) dan kelas kontrol menggunkan model pembelajaran konvensional yakni ceramah dan tanya jawab klasikal. Kegiatan pembelajaran dilakukan secara langsung oleh peneliti sebagai guru di kelas eksperimen dan kelas kontrol. Penelitian dilaksanakan dalam waktu 4 minggu dengan jumlah pertemuan sebanyak 4 kali di kelas eksperimen dan kelas kontrol.

Analisis data penelitian yang dilakukan yakni uji normalitas menunjukkan $\mathrm{L}_{\mathrm{o}}<\mathrm{L}_{\mathrm{t}}$ dimana $\mathrm{L}_{\mathrm{o}}=0,1325$ dan $\mathrm{L}_{\mathrm{t}}=0,1528$ sehingga dapat dinterpretasikan bahwa data telah terdistribusi normal. Sedangkan, uji homogen yang diperoleh menunjukkan $F_{h}<F_{t}$ dimana $F_{h}=1,1209$ dan $F_{t}=1,84$, dari hasil ini dapat diinterpretasikan bahwa sampel yang digunakan sudah homogen. Setelah mengetahui data terdistribusi normal dan homogen, dapat dilakukan uji t. Uji t yang dilakukan mendapatkan hasil $t_{\text {hitung }}>t_{\text {tabel }}$ yaitu 18,08 $>1,66$ maka dapat diinterpretasikan bahwa model pembelajaran kooperatif tipe NHT memiliki pengaruh terhadap kemampuan berpikir kritis.

Hasil penelitian di kelas eksperimen menunjukkan siswa memperoleh nilai rata-rata pretes sebesar 36,97 dan untuk nilai rata-rata postes 80,35 . Sedangkan, di kelas kontrol rata-rata pretes sebesar 36,8 dan untuk nilai rata-rata postes 75,7 .

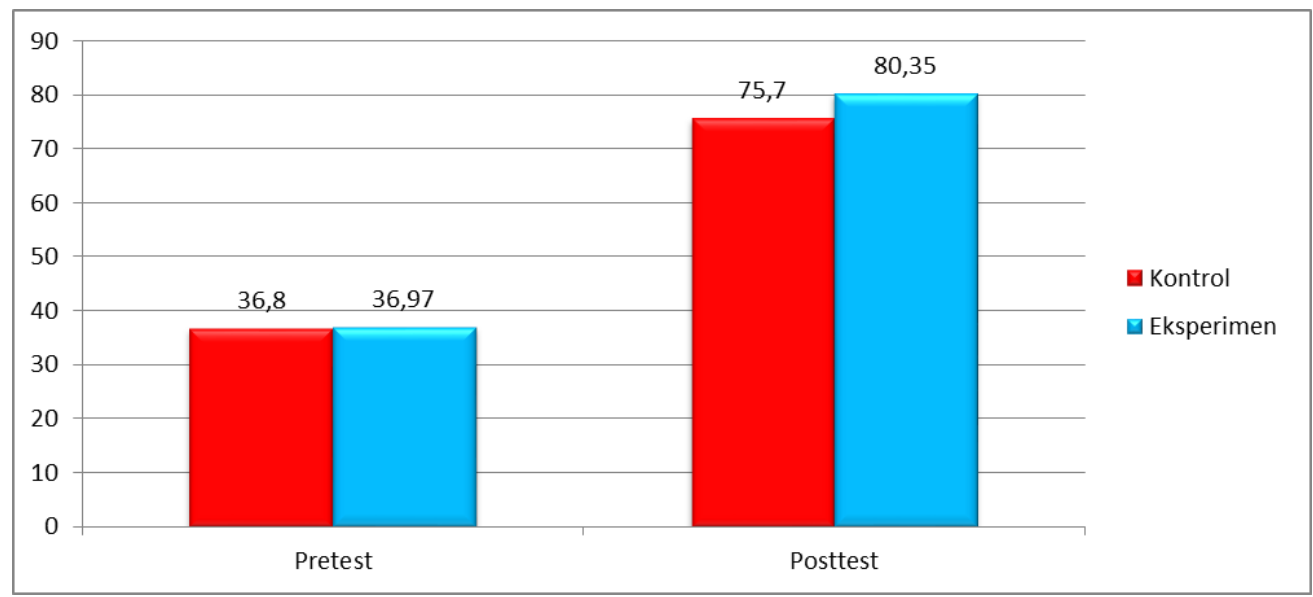

Gambar 2. Perbedaan hasil pretest dan postest

Setelah dihitung effect size, didapatkan indeks effect size sebesar 0,3. Indeks effect size sebesar 0,3 ini dapat diinterpretasikan bahwa kelompok eksperimen sebesar $62 \%$ lebih baik dari kelompok kontrol. Tabel 4 kolom ke enam memberikan informasi bahwa NHT dapat meningkatkan kemampuan berpikir kritis dengan indeks 0.58 artinya jika diambil sampel secara acak maka dapat dipastikan 58 orang dari 100 orang dapat meningkat kemampuan berpikir kritisnya dengan menggunakan model pembelajaran kooperatif tipe NHT.
Bagaimana NHT dapat mempengaruhi berpikir kritis? Sebagaimana disampaikan Tileston (2007) bahwa NHT adalah salah satu pembelajaran aktif. Pembelajaran menggunakan NHT menjadikan semua siswa terlibat aktif, mulai dari mengidentifikasi masalah, menganalisa dan mengevaluasi masalah yang juga merupakan proses tingkat berpikir kritis. Oleh sebab itu, NHT dapat dengan mudah mendukung proses berpikir kritis. Saat persoalan yang diberikan guru kepada siswa, siswa melakukan identifikasi masalah, memberikan hipotesis terhadap 
masalah, kemudian menganalisa masalah dan mendiskusikan masalah tersebut dalam kelompok sehingga siswa bisa memberikan evaluasi kritis terhadap permasalahan yang diberikan guru. Sikap mengidentifikasi masalah, memberikan hipotesis, menganalisa, mendiskusikan dan mengevaluasi merupakan sikap ilmiah (Kucel, Robert, Buil, \& Masferrer, 2016). Sikap ilmiah sangat familiar pada pembelajaran fisika pada setiap konten fisika yang dipelajari. Jadi karakteristik pembelajaran fisika dengan model pembelajaran kooperatif tipe NHT mempunyai kecocokan dan saling mendukung satu sama lain.

NHT mudah diterapkan dalam pembelajaran (Kagan, 2011), sehingga memudahkan tercapainya tujuan pembelajaran dan meningkatkan proses berpikir kritis. Langkah-langkah sederhana NHT mudah dimengerti siswa sehingga dapat mengoptimalkan pembelajaran. Tahapan pembelajaran yang mudah dimengerti sangat diperlukan dalam penerapan pembelajaran, agar siswa tidak terbebani dengan langkah yang rumit tapi dapat fokus pada konten pembelajaran sehingga membangun konsep pembelajaran dengan baik (Kolayis, Sari, \& Celik, 2014).

\section{SIMPULAN DAN SARAN}

Model pembelajaran kooperatif tipe NHT dapat mempengaruhi kemampuan berpikir kritis dengan indeks effezt size sebesar 0.7 dengan persentase $76 \%$ lebih baik dari pembelajaran konvensional (ceramah dan tanya jawab klasikal).

NHT dapat menghasilkan outcome pembelajaran berupa kemampuan berpikir kritis dengan indeks 0,69 yang berarti setiap 100 sampel acak, NHT dapat mempengaruhi 69 orang untuk meningkatkan kemampuan berpikir kritis.

\section{DAFTAR PUSTAKA}

Abidin, Y. (2016). Revitalisasi Penilaian Pembelajaran. Bandung: Refika Aditama.

Abrami, P. C., Bernard, R. M., Borokhovski, E., Waddington, D. I., Wade, C. A., \& Persson, T. (2015). Strategies for Teaching Students to Think Critically: A Meta Analysis. Review of Educational Research, 85(2), 275314.

doi:10.3102/00346554314551063

Anas, S. (2013). Pengantar Evaluasi Pendidikan. Jakarta: Rajawali Pers.

Arikunto, S. (2013). Dasar-dasar Evaluasi Pendidikan. Jakarta: Bumi Aksara.

Badan Standar Nasional Pendidikan (BSNP). (2006). Peraturan Menteri Nomor 22 Tahun 2006 Tentang Standar Isi. Jakarta.

Baker, D. P. (2013). The Effects of Impementing the Cooperative Learning Structure, Mumered Heads Together, in Chemistery Classes at Rural, Low Performing High School. Louisiana: The Louisiana State University.

Beaumont, J. (2010). A Sequence of Critical Thinking Tasks. Tesol Journal, 1-22.

Coe, R. (2002). It's the Effect Size, Stupid: What Effect Size Is and Why It Is Important. The British Educational Research Association Annual Conference. England: The British Educational Research Association.

Cohen, J. (1988). Statiscal Power Analysis for the behavioral Science Second Edition. United States of America Associates: Lawrence Erlbaum .

Cohen, J. (1992). A Power Primer. Psychological Bulletin, 112(1), 155-159. doi:10.1037/00332909.112.1.155

Fritz, C. O., \& Morris, P. E. (2012). Effect Size Estimates: Current Use, Calculations, and Interpretation. Journal of Experimental 
Psychology, 14(1), 2-18. doi: $10.1037 / \mathrm{a} 0024338$

Greene, J. A., \& Yu, S. B. (2015). Educating Critical Thinkers: The Role of Epistemic Cognition. Behavioral and Brain Scences, 4553.

doi:10.1177/2372732215622223

Hake, R. R. (2002). Relationship of Individual Student Normalized Learning Gains in Mechanics with Gender, High School Physics, and Pretest Scores on Mathematics and Spatial Visualization. The Physics Education Research Conference Proceedings. Boise: he Physics Education Research.

Henderson, C., Mestre, J. P., \& Slakey, L. L. (2015). Cognitive Science Research Can improve Undergraduate STEM Instruction: What are the Barriers. Behavioral and Brain Sciences, 2(1), 51-60. doi:10.1177/2372732215601115

Johnson. (2016, October 7). Experimental Research. Retrieved from University of South Alabama: http://southalabama.edu

Kagan. (2011). Numbered Heads Together: The Quiz Show Review Game. Kagan Publishing.

Kolayis, H., Sari, I., \& Celik, N. (2014). The Comparison of Critical Thinking and Problem Solving Disposition of Athletes According to Gender and Sport Type. Internasional Journal of Human Sciences, $\quad 11(2), \quad 842-849$. doi:10.14687/ijhs.y11i2.3051

Krathwohl, D. R. (2002). A Revision of Bloom's Taxonomy: An Overview. Theory Into Practice, 41(4), 212218.

Kucel, A., Robert, P., Buil, M., \& Masferrer, N. (2016). Enterpreneurial Skill and Education-Job Matching of Higer Education Graduates. European
Journal of Education, 51(1), 73-89. doi:10.1111/ejed.12161

Lakens, D. (2013). Calculating and Reporting Effect Size to Facilitate Cumulative Science: a Practical Primer for $\mathrm{t}$ Tests and ANOVAs. Frontiers in Psychology, IV, 1-12. doi:10.3389

Lau, J., \& Chan, J. (2016, October 5). What Is Critical Thinking. Retrieved from Critical Thinking Web: http://www.philosophy.hku.hk

Miller, T., Chahine, S., \& Childs, R. A. (2010). Detecting Diferential Item Functioning and Differential Step Functioning Due to Diffrences that Shold Matter. Practical Assessment Research and Evaluation, 15(10), 1-13.

Paul, R., \& Elder, L. (2008). Why Critical Thinking. Retrieved from The Critical Thinking Community: http://www.criticalthinking.org

Peter Haussler, L. H. (2000). A curricular Frame for Physics Education: Development, Comparison with Students Interests, and Impact on Students Achievement and Self Concept. Science Education, 84(6), 689-705. doi:10.1002/1098237x(200011)84:6<689::AIDSCE1>3.0CO;2-L

Peter, E. E. (2012). Critical Thinking: Essence for Teaching Mathematics and Mathematics Problem Solving Skills. African Journal of Mathematics and Computer Science Research, V(3), 39-43. doi:10.5897/AJMCSR11.161

Sani, R. A. (2014). Inovasi Pembelajaran. Jakarta: Bumi Aksara.

Sin, C. (2014). Epistemology, Sociology, and Learning an Teaching in Physics. Science Education, 98(2), 342-365. doi:10/1002/SCE. 21100

Slavin, R. E. (2009). Cooperative Learning: Teori, Riset dan Praktik. Bandung: Penerbit Nusa Media. 
Sugiono. (2013). Metode Penelitian Pendidikan Pendekatan Kuantitatif dan Kualitatif dan $R \quad \& \quad D$. Bandung: Alfabeta.

Sugiyono. (2008). Statistik Untuk Penelitian. Bandung: Alfabeta.

Tileston, D. W. (2007). Teaching Strategies for Active Learning. California: Corwin Press.

Wati, W. (2009). Upaya Meningkatkan Aktivitas dan Hasil Belajar Fisika Siswa dengan Menerapkan Model Coopertive Learning Type Student Teams Achievement Division (STAD) dengan Media Microsoft Powerpoint di Kelas XI.2 Man Cendiakia Jambi. Jambi: Universitas Negeri Jambi.

Wati, W. (2012). The Development of Physics Material Learning Based Character Education with Model of Cooperative Learning. Sumatera Barat: Universitas Negeri Padang.
Wati, W., \& Novianti. (2016). Developing Assessment Rubric Skill Process in Junior High School Science Learning. Jurnal Ilmiah Pendidikan Fisika Al Biruni, 131140.

Wati, W., Asyhari, A., \& Diani, R. (2016). The Development of Learning Printed Materials Physics Based Character Education with Model of Cooperative Learning. Seminar Nasional Pendidikan (pp. 282295). Bandar Lampung: pendidikan Fisika FKIP Universitas Lampung.

York, T. T., Gibson, C., \& Rankin, S. (2015). Defining and Measuring Academic Succsess. Practical Assessment Research and Evaluastion, 20(5), 1-36. 